\title{
A fuzzy-based model to implement the global safety buildings index assessment for agri-food buildings
}

\author{
Francesco Barreca, Giuseppe Cardinali, Carmelo Riccardo Fichera, Luigi Lamberto, \\ Giuseppe Modica \\ Dipartimento di Agraria, Università degli studi Mediterranea, Reggio Calabria, Italy
}

\begin{abstract}
The latest EU policies focus on the issue of food safety with a view to ensuring adequate and standard quality levels for the food produced and/or consumed within the EC. To that purpose, the environment where agricultural products are manufactured and processed plays a crucial role in achieving food hygiene. As a consequence, it is of the outmost importance to adopt proper building solutions which meet health and hygiene requirements as well as to use suitable tools to measure the levels achieved. Similarly, it is necessary to verify and evaluate the level of workers' safety and welfare in their working environment. Workers' safety has not only an ethical and social value but also an economic implication, since possible accidents or environmental stressors are the major causes of the lower efficiency and productivity of workers. Therefore, it is fundamental to design suitable models of analysis that allow assessing buildings as a whole, taking into account both health and hygiene safety as well as workers' safety and welfare. Hence, this paper proposes an assessment model that, based on an established study protocol and on the application of a fuzzy logic procedure, allows assessing the global safety level of an agri-food building by means of a global
\end{abstract}

Correspondence: Francesco Barreca, Dipartimento di Agraria, Università degli studi Mediterranea di Reggio Calabria, Località Feo di Vito, 89122 Reggio Calabria, Italy.

E-mail: fbarreca@unirc.it

Key words: agri-food buildings design, fuzzy set, global safety buildings index, inferential fuzzy rules, safety performance assessment.

Acknowledgements: the authors are grateful to Dr. Pavel Holeček for providing the trial of FuzzME software package (Faculty of Science, Palacký University Olomouc; http://fuzzme.wz.cz/).

Funding: this research was partly funded by QUASIORA (Quality Safety Origin of food) project, which was granted within the Framework Program APQ Ricerca Scientifica e Innovazione Tecnologica nella Regione Calabria (Scientific Research and Technological Innovation in the Calabria Region) and involved the European Union, the Calabria Region and the Italian Ministry for Education, University and Research.

Received for publication: 11 January 2014.

Accepted for publication: 2 April 2014.

(C) Copyright F. Barreca et al., 2014

Licensee PAGEPress, Italy

Journal of Agricultural Engineering 2014; XLV:227

doi:10.4081/jae.2014.227

This article is distributed under the terms of the Creative Commons Attribution Noncommercial License (by-nc 3.0) which permits any noncommercial use, distribution, and reproduction in any medium, provided the original author(s) and source are credited. safety buildings index. The model here presented is original since it uses fuzzy logic to evaluate the performances of both the technical and environmental systems of an agri-food building in terms of health and hygiene safety of the manufacturing process as well as of workers' health and safety. The result of the assessment is expressed through a triangular fuzzy membership function which allows carrying out comparative analyses of different buildings. A specific procedure was developed to apply the model to a case study which tested its operational simplicity and the validity of its results. The proposed model allows obtaining a synthetic and global value of the building performance of each of its functional areas, in terms of food hygiene and workers' safety and welfare, as well as highlighting possible weaknesses. Though the model may be applied in either the design or the operational phase of a building, this paper focuses on its application to certain buildings already operating in a specific productive context.

\section{Introduction}

Recent statistical surveys show that, in Europe (Eurostat, 2010), food manufacturing companies are about 264,100 and workers in the sector are over 4,092,000, for an annual turnover of over 813 billion Euros. These figures give an idea of the importance of this productive sector and, above all, of its significance for the whole European economy. On the other hand, consumers demand more and more guarantees of safety and sustainability of the entire chain of production.

In order to ensure suitable health and hygiene standards, it is fundamental to consider the whole production cycle in all types of agrifood companies: from the supply of raw material to the sale of the product. In fact, during all the phases of its manufacture, the product risks of being contaminated by pathogenic microorganisms for reasons related not only to the manufacturing process but also to the indoor environmental conditions of hygiene of the facility, which are strictly connected with the adopted technical and management solutions (Lelieveld et al., 2005).

However, agri-food facilities must ensure not only the consumers' hygiene safety, by adopting all the precautions and building solutions which may guarantee adequate safety levels for product contamination, but also an adequate safety level for workers (Sinisammal et al., 2012). Recently, EU-27 has implemented the European 2007-2012 strategy on health and safety at work (European Commission, 2007) establishing six intermediate objectives in order to achieve a $25 \%$ reduction in the total incidence rate of accidents at work. As recently reported, the Strategy has met this ambitious goal. Currently, the 20132020 Health and Safety Strategy is still under implementation.

Therefore, manufacturing facilities should ensure adequate performances in terms of health and hygiene standards and of workers' safety (Jacinto et al., 2009; Fabiano et al., 2004). These performances should be carefully taken into account during the building design process and regularly verified during its use. To that purpose, post 
occupancy evaluation (Joon-Hoa et al., 2012; Di Fazio and Barreca, 2009) is particularly important. Another significant aspect to consider is that the building performances may also depend on how the manufacturing process is managed and conducted (Leppälä, 2012). For instance, hygiene conditions are influenced by sanitation procedures and the noise level is strictly connected with the machines, plants and operation modes used (Parejo-Moscoso et al., 2013).

The main goal of the research is to obtain a synthetic value of global safety that can be referred exclusively to the building and to its components and plants. Specifically, this paper proposes a model for the assessment of the global safety building index (GSBI) that takes into account only the performances of the technical elements and plants of the building (Porceddu and Babucci, 2007) and does not consider the contingent conditions of the manufacturing process and, therefore, the company operation modes (Barreca et al., 2010; Stave and Törner, 2007; Dioguardi and Franzetti, 2008; Seaman, 2010). This approach allows applying the model also in the design phase and assessing the global safety level of the building even before it starts operating. Thus, the model highlights the most important weaknesses in global safety and verifies the effects of possible interventions and corrections.

\section{Materials and methods}

\section{The model for global safety buildings index assessment}

The global safety buildings index can be defined as a synthetic value used to assess and estimate the global safety level of an agri-food building in relation to workers' health and food hygiene quality.

The building system evaluation, encapsulated through GSBI, is carried out by means of specific performance indicators referring to operator safety (OS) and hygienic safety (HS) (Figure 1). In more details, GSBI was implemented to assess OS and HS performances for each of the following functional areas of an agri-food building: i) receiving; ii) processing; iii) packaging; iv) storing; v) support.

Such indicators can be measured objectively, through an instrumental survey, or subjectively, through a qualitative judgment expressed by an expert surveyor. GSBI set of indicators was organized into a fivelevel hierarchical structure (Figure 1). In particular, the first level was divided into the two established safety categories: OS and HS. This hierarchisation allowed evaluating such categories for each functional area (FA) of the building, thus showing in which of them the building could reveal greater weaknesses. For each FA on the second hierarchical level, the adequacy of the technical system (building components which are directly related to safety) and the environment safety (referred to the performances of the class of the technical elements that indirectly contribute to creating internal environmental and functional conditions that enhance safety) were assessed.

\section{Set of quantitative and qualitative indicators}

The methodology used for GSBI assessment offers the possibility to analyze not only the overall safety of a building, but also the disaggregated values for each FA. It also allows bringing out issues that are critical to properly design targeted building solutions. In the specific case study dealt with in this paper, the implementation of the procedure allowed verifying the appropriateness of the developed model and its ease of application. To that purpose, in the phase of the model definition, particular importance was given to the determination of the sets of indicators concerning the hygienic safety of products and the workers' safety. Specifically, though indicators were limited in number to facilitate the phase of data acquisition and the application of the model, they were chosen according to the following characteristics: i) being easy to assess by means of not particularly complex instruments; ii) being exclusively referred to technical building components; iii) being independent from contingent factors or from the boundary conditions of the manufacturing process; iv) being independent for each function$\mathrm{al}$ area and field of assessment.

In fact, the number of assessment indexes should be adequate to describe the building performances correctly and quite accurately in relation to health and hygiene safety and workers' safety and should take into account current regulations and the most dangerous risks inside buildings. On the basis of their different typology, quantitative and qualitative indicators were distinguished. Quantitative indicators are characteristics of the building that can be instrumentally measured or evaluated through calculation procedures; while qualitative indicators are based on the judgment of a surveyor/assessor (Table 1).

For instance, in the category of workers' safety, the slip, trip and fall safety of the building was assessed. The risks of slipping and tripping are among the main risk factors for workers in the agri-food sector. The loss of grip between foot and floor may be induced either by an inadequate value of floor roughness or by the presence of liquids that alter the surface of the material, or by both conditions. A useful element to quantify the workers' risk of slipping is the measurement of the coefficient of sliding friction between sole and floor (Malkin and Harrison, 1980). The proposed model assessed fall safety by referring to the following specific indicators: slipping on wet and dry floor; tripping due to loss of balance; quick liquid removal from the floor. Indicators were assessed by referring to instrumental measurements. For instance, slip safety was evaluated by measuring slipperiness with the Tortus method, developed by Malkin and Harrison at British Ceramic Research Association (1980) and based on the measurement of the sliding friction value of a slipping element (in rubber for wet floors; in leather for dry floors). Slipperiness was measured by means of a Tortus digital tribometer (Figure 2).

\section{Data analysis and aggregation}

The numerical analysis and the aggregation of the values of the qualitative and quantitative indicators were carried out by means of fuzzy logic (Abouelnaga et al., 2010; Beriha et al., 2012). The main property of fuzzy logic (Zadeh, 1965) is that it translates linguistic judgments, generated by human reasoning in a vague and inaccurate manner, into numerical and mathematical terms. Therefore, the use of this logic allows overcoming the uncertainty of the qualitative assessment of the single technical building element, which is conducted by a surveyor, as well as considering the difficulty in estimating how the performance of each component contributes to the value of the global safety of the building (Pinto et al., 2012). Furthermore, the standardisation of values in hierarchical levels allows expressing GSBI in a variable interval between 0 and 1 , where 0 corresponds to the worst value while 1 corresponds to the best one.

The model was implemented by means of fuzzy methods of multiple criteria evaluation (FuzzME), a software specifically developed to create and use fuzzy models of multiple-criteria evaluation and decision making (Holeček and Talašová, 2010). The values of indicators were transformed into fuzzy membership values by using a specific transformation function of triangular type that took into account three levels of judgment (low, acceptable, good). For instance, in the case of slip safety, safety was low if the coefficient of sliding friction was below 0.4 ; it was acceptable if the coefficient was between 0.4 and 0.74 ; and, finally, it was good if the coefficient was above 0.74 .

The aggregation of the values of indicators was carried out by means of inferential fuzzy rules that were generated using a modified TakagiSugeno fuzzy-model (Takagi and Sugeno, 1985): the so-called Sugeno weighted average method (Sugeno-WA). An important advantage of this 
aggregation method is that the result is also a fuzzy number. The use of inferential fuzzy rules allowed assessing criteria according to pre-set combinations of fuzzy membership values (Figure 3) and taking into account possible non-linear correlations between performance indicators. For example, it was possible to set a negative performance of a criterion if even one indicator had a performance below a normative limit. The other levels composing the hierarchical model were aggregated in relation to the elements belonging to the same hierarchical level by means of a normalised fuzzy weighted average procedure. The weights of each level of assessment, whose sum was equal to 1 (Figure 1), were defined with a group of field experts. In particular, the relative weight of each element was defined through the pairwise comparison of elements belonging to the same group and took into account the following aspects: contribution to global safety; level of measurement accuracy; adopted measurement method (instrumental or subjective); literature data; acquired scientific knowledge; reference values of National and International regulations.

Table 1. List of the surveyed indicators showing their units of measurement.

\begin{tabular}{|c|c|c|c|}
\hline Criterion & Indicator & Type & UM \\
\hline \multicolumn{4}{|c|}{ Hygienic safety } \\
\hline Services sanitation & $\begin{array}{l}\text { Changing rooms prevention } \\
\text { Communication between areas/services } \\
\text { Opening control valves efficiency } \\
\text { Drying equipment efficiency }\end{array}$ & $\begin{array}{l}\text { Qualitative } \\
\text { Qualitative } \\
\text { Qualitative } \\
\text { Qualitative }\end{array}$ & $\begin{array}{l}\text { Linguistic } \\
\text { Linguistic } \\
\text { Linguistic } \\
\text { Linguistic }\end{array}$ \\
\hline Sanitation systems air & Sanitation systems air & Qualitative & Linguistic \\
\hline Air pollution & $\begin{array}{c}\text { Vegetation proximity } \\
\text { Distance sources of contaminants }\end{array}$ & $\begin{array}{l}\text { Quantitative } \\
\text { Quantitative }\end{array}$ & $\begin{array}{l}\mathrm{m} \\
\mathrm{m}\end{array}$ \\
\hline Water disposal system & $\begin{array}{c}\text { U-bend type } \\
\text { Material traps } \\
\text { N. Trap/area served }\end{array}$ & $\begin{array}{l}\text { Qualitative } \\
\text { Qualitative } \\
\text { Quantitative }\end{array}$ & $\begin{array}{l}\text { Linguistic } \\
\text { Linguistic } \\
\mathrm{m}^{-2}\end{array}$ \\
\hline Floor removing liquids & Floor removing liquids & Quantitative & $\%$ \\
\hline Cleanability floors & $\begin{array}{l}\text { Cleanability tile joints } \\
\text { Cleanability of the surfaces } \\
\text { Floor material }\end{array}$ & $\begin{array}{l}\text { Qualitative } \\
\text { Qualitative } \\
\text { Qualitative }\end{array}$ & $\begin{array}{l}\text { Linguistic } \\
\text { Linguistic } \\
\text { Linguistic }\end{array}$ \\
\hline Cleanability fittings & Cleanability fittings & Qualitative & Linguistic \\
\hline Disinfection vertical coating & $\begin{array}{l}\text { Cleanability tile joints } \\
\text { Vertical coating material } \\
\text { Height vertical coating }\end{array}$ & $\begin{array}{l}\text { Qualitative } \\
\text { Qualitative } \\
\text { Quantitative }\end{array}$ & $\begin{array}{l}\text { Linguistic } \\
\text { Linguistic } \\
\mathrm{m}\end{array}$ \\
\hline Indoor environment & Indoor environment & Qualitative & Linguistic \\
\hline Access pest animals & $\begin{array}{l}\text { Switch between areas } \\
\text { External access }\end{array}$ & $\begin{array}{l}\text { Qualitative } \\
\text { Qualitative }\end{array}$ & $\begin{array}{l}\text { Linguistic } \\
\text { Linguistic }\end{array}$ \\
\hline Nesting & Nesting & Qualitative & Linguistic \\
\hline \multicolumn{4}{|c|}{ Operator safety } \\
\hline Indoor environment & Indoor environment & Qualitative & Linguistic \\
\hline Access pest animals & $\begin{array}{c}\text { Switch between areas } \\
\text { External access }\end{array}$ & $\begin{array}{l}\text { Qualitative } \\
\text { Qualitative }\end{array}$ & $\begin{array}{l}\text { Linguistic } \\
\text { Linguistic }\end{array}$ \\
\hline Nesting & Nesting & Qualitative & Linguistic \\
\hline Indoor quality & $\begin{array}{c}\text { Ventilation's ratio } \\
\text { Air conditioning systems }\end{array}$ & $\begin{array}{l}\text { Quantitative } \\
\text { Qualitative }\end{array}$ & $\begin{array}{c}\% \\
\text { Linguistic }\end{array}$ \\
\hline Noise & $\begin{array}{l}\text { Noise control devices } \\
\text { Reverberation time }\end{array}$ & $\begin{array}{l}\text { Qualitative } \\
\text { Quantitative }\end{array}$ & $\begin{array}{l}\text { Linguistic } \\
\mathrm{S}\end{array}$ \\
\hline Thermal wellness & $\begin{array}{l}\text { Energy class } \\
\text { Pmv }\end{array}$ & $\begin{array}{l}\text { Quantitative } \\
\text { Quantitative }\end{array}$ & $\begin{array}{c}\mathrm{W} \cdot \mathrm{s} \cdot \mathrm{m}^{-2} \cdot \mathrm{a}^{-1} \\
\mathrm{pmv}\end{array}$ \\
\hline Light conditions & $\begin{array}{l}\text { Artificial lighting level } \\
\text { Daylight factor }\end{array}$ & $\begin{array}{l}\text { Quantitative } \\
\text { Quantitative }\end{array}$ & $\begin{array}{c}\operatorname{lux} \\
\%\end{array}$ \\
\hline Fire protection & $\begin{array}{l}\text { Distance from safe places } \\
\text { Start fire } \\
\text { Fire protection } \\
\text { Fire resistance }\end{array}$ & $\begin{array}{l}\text { Quantitative } \\
\text { Quantitative } \\
\text { Qualitative } \\
\text { Quantitative }\end{array}$ & $\begin{array}{c}\mathrm{m} \\
\mathrm{J} \cdot \mathrm{m}^{-2} \\
\text { Linguistic } \\
\mathrm{s}\end{array}$ \\
\hline Electric system & Electric system & Qualitative & Linguistic \\
\hline Fall safety & $\begin{array}{c}\text { Stumbling } \\
\text { Dry floor slipperiness } \\
\text { Disposal water surface area } \\
\text { Wet floor slipperiness }\end{array}$ & $\begin{array}{l}\text { Quantitative } \\
\text { Quantitative } \\
\text { Quantitative } \\
\text { Quantitative }\end{array}$ & $\begin{array}{c}\% \\
\text { num } \\
\% \\
\text { num }\end{array}$ \\
\hline Service space & Service space & Qualitative & Linguistic \\
\hline
\end{tabular}

UM, units of measurement; Pmv, predicted mean vote. 


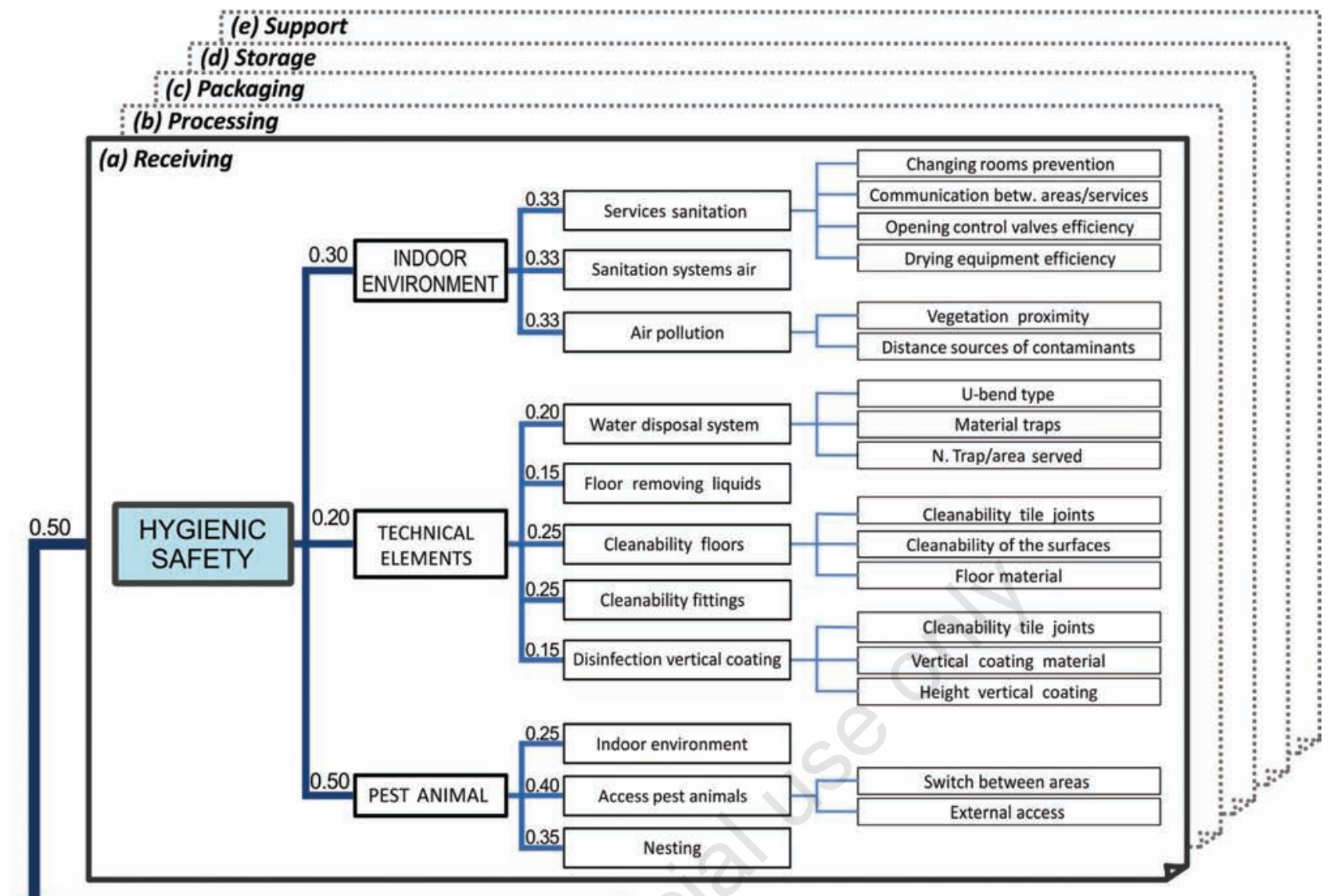

\section{GSBI - Global Safety Building Index}

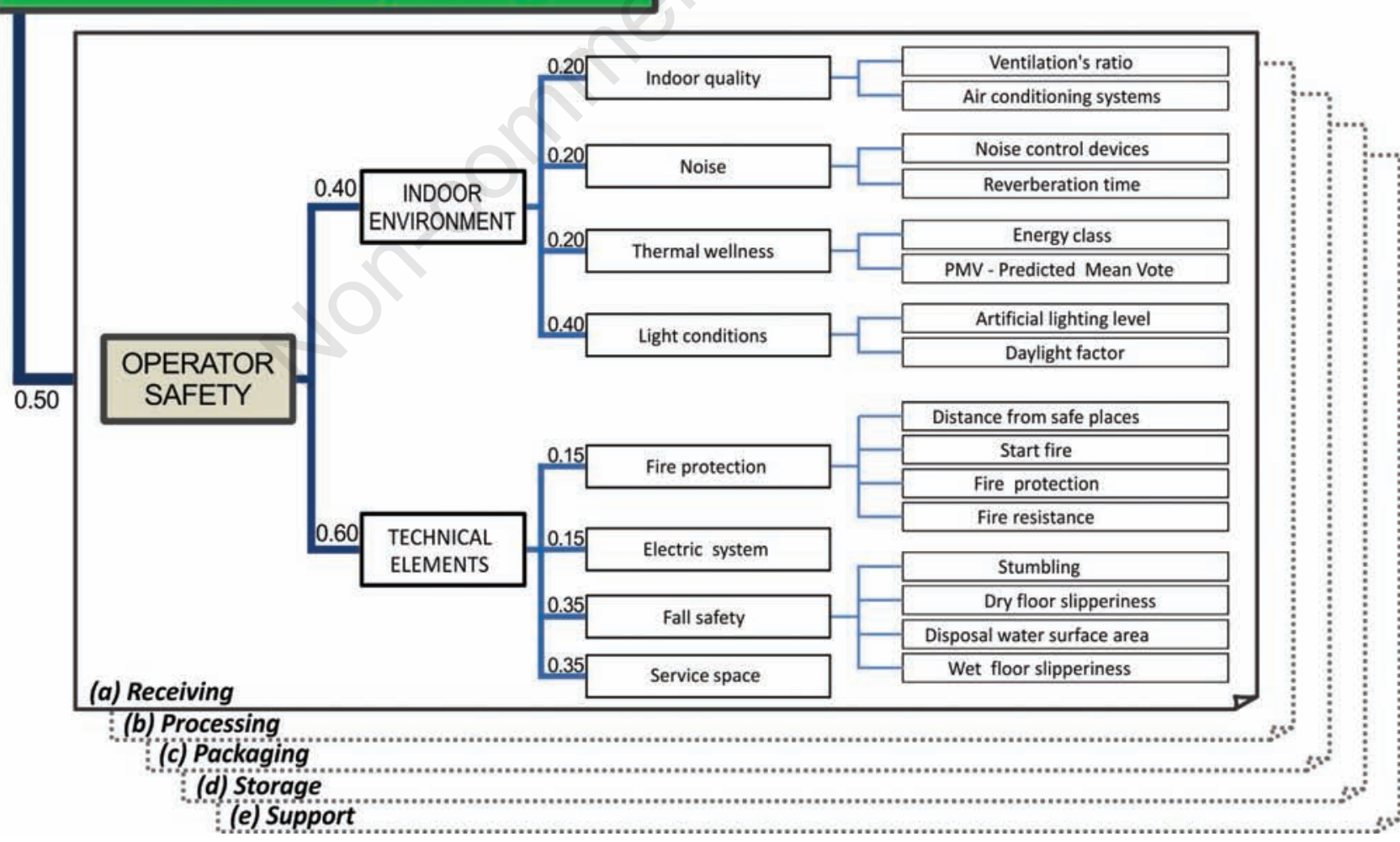

Figure 1. Logical schema showing the five-level hierarchical structure of the model for the assessment of the global safety buildings index. Weights used to aggregate criteria, the technical and environmental systems and the categories composing the model are also shown. They are the same for all the five functional areas. 


\section{Results and discussion}

The model was first calibrated on a theoretical example of a standard manufacturing facility. In particular, a parametric variation in the values of the main indicators was simulated and the consequent variation in the model results was analysed. The values obtained from the theoretical buildings showing the highest and the lowest global safety levels were carefully observed and chosen as benchmarks.

The validation of the model required the development of a specific procedure (Figure 4) made up of consecutive steps that allowed checking proper progress and making corrections in each phase. In particular, such steps can be summarised as follows:

- Planning of the survey campaign and preliminary investigation with a building survey of the manufacturing facility.

- Collection of data on the company that uses the building and on its organization.

- Recording and acquisition of detailed data and performance assessment of the building and of its components through instrumental measurements and evaluation judgments expressed by the surveyor and organised according to a specially prepared checklist.

Data analysis and verification of the congruency of recorded data and measures with the performance specifications of the elements.

Compilation of the checklist and filling in of a survey form.

- Input of the acquired data in the analysis model and transformation of data into fuzzy values.

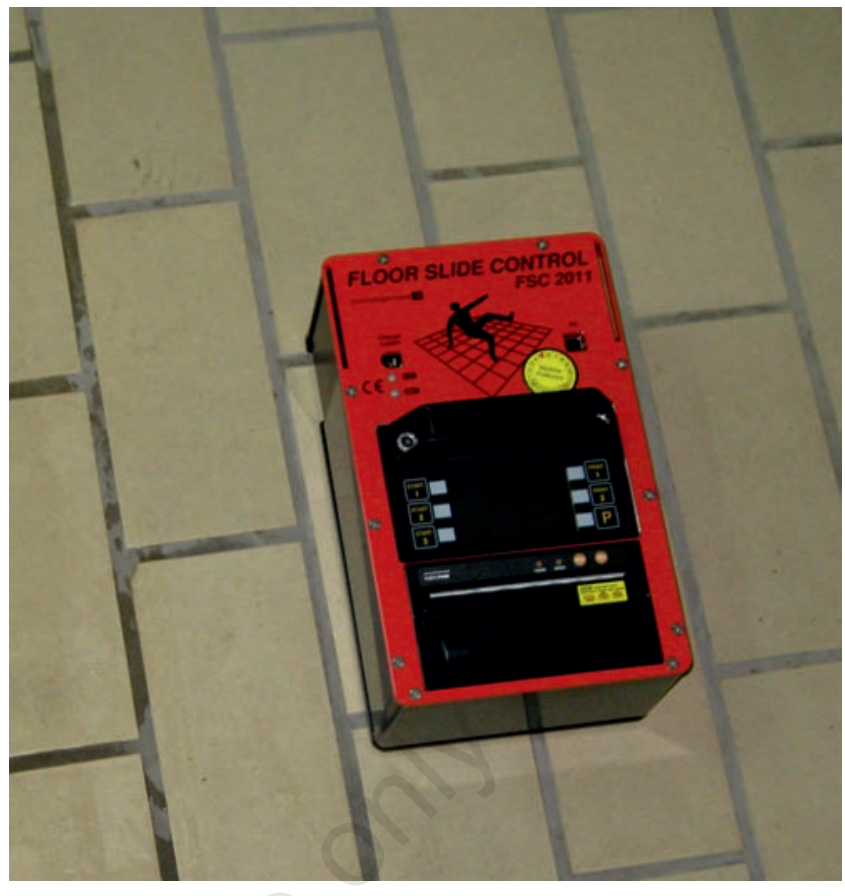

Figure 2. Survey of coefficient of friction on the floor by the Tortus digital tribometer.
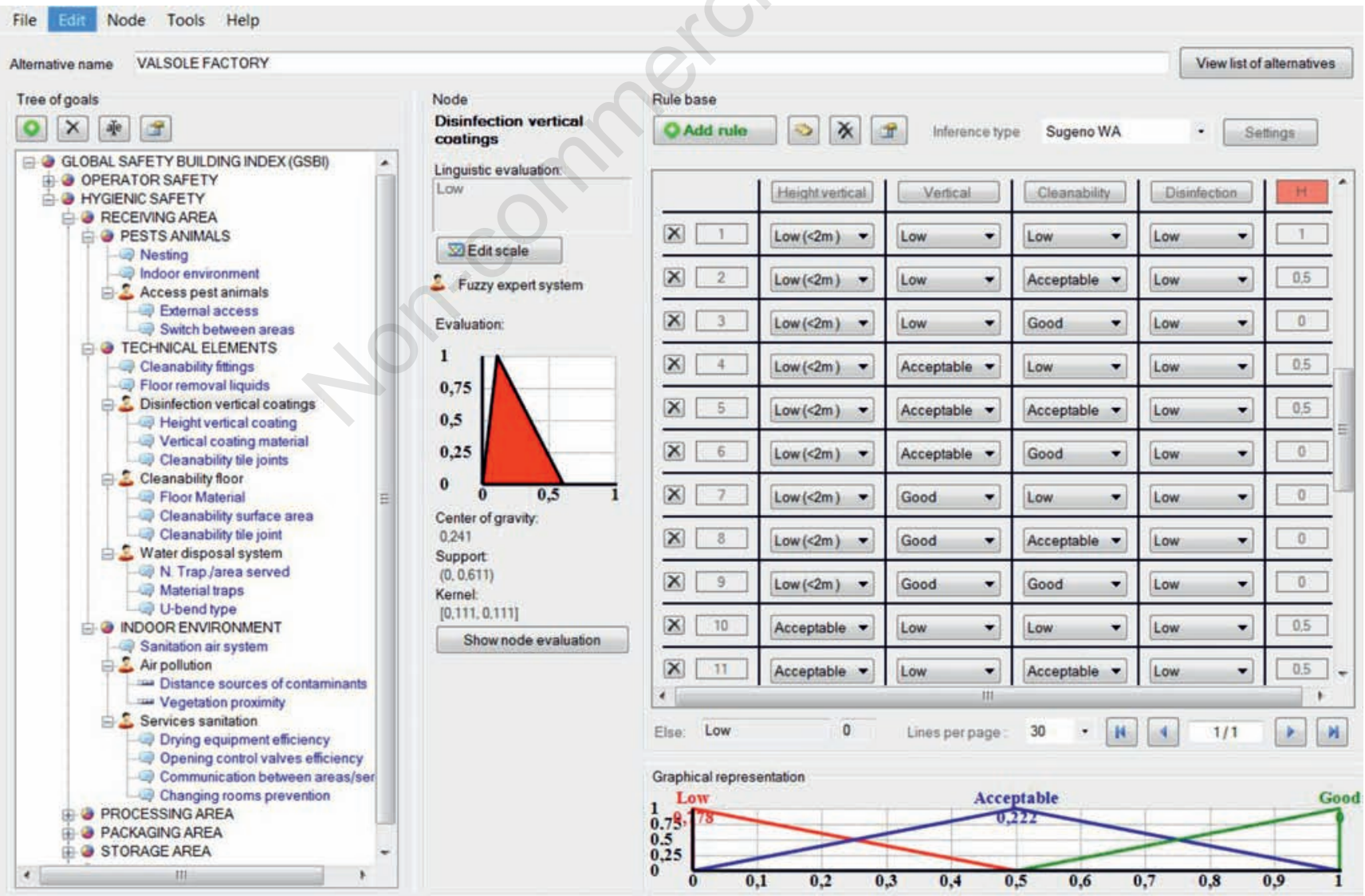

Figure 3. Fuzzy rule base created in FuzzMe software for the assessment of the disinfection of vertical coatings. 
- Implementation of the model of analysis in the FuzzMe environment and aggregation of the different hierarchical levels through established weight functions.

- Verification of the consistency of the results obtained from the model and possible adjustment and improvement of data.

- Comparison and analysis of the results obtained from the model, observations on the results obtained in the different hierarchical levels of the model.

- Calculation of GSBI and of the relative values for each functional area and category.

- Analysis and identification of possible weaknesses in health and hygiene safety and in workers' safety.

- Development of possible proposals and corrections on the building in order to improve performances in the hygienic safety of products and in the workers' safety.

At this point, the application of the model may end or, starting a loop procedure from the initial phases of surveying, it may allow verifying the effectiveness of the corrections put in place or only envisaged.

This organization of the model allows assessing the global safety level of the building or calculating it already during the phase of design. Moreover, it enables to verify the effectiveness of possible corrections or modifications in the technical elements of the buildings. In addition, the possibility to compare the value of the global safety of the building to the established benchmark values is particularly important.

The whole procedure was applied to the manufacturing area of a dairy farm located in the plain of Gioia Tauro (Calabria, Italy). The chosen type of building is widespread in the Southern Italy, where most dairy farms are small- or medium-sized. Furthermore, the application of the model to this building, which was recently completed (in the late 2011), enabled to test the effectiveness of the technical solutions that are commonly adopted in this type of construction. The manufacturing facility covers two storeys, each of about $250 \mathrm{~m}^{2}$; the manufacturing area is located on the ground floor and covers around $130 \mathrm{~m}^{2}$ (Figure 5 ). The production cycle takes place every day and generally concerns fresh cheese, mozzarella and cottage cheese, which are directly marketed for the most part.

After a first inspection, the building was surveyed and then, following the checklist, metrical data and judgments on the performance of the main building components, in terms of hygienic safety of the products and workers' safety, were acquired.

The values of the fuzzy functions obtained from the application of the proposed model (Figure 5) allowed carrying out a first series of analyses and evaluations on the safety level of the manufacturing area of the building concerned.

The resulting fuzzy function, which represents the global safety of the building, is centrally positioned between the two maximum and minimum functions and has an acceptable uncertainty value of 0.332 . This value depends on the inferential rules and aggregation procedures used by the model. In particular, inference through Sugeno OWA method provided less dispersed values than Mamdami's method (Mamdani and Assilian, 1975).

In particular, the geometric centre of the fuzzy function, which describes global safety, calculated through the illustrated procedure, has a value (0.44) that is slightly lower than the average value $(0.50)$. This means that the global safety of the building is certainly acceptable, even if it shows further room for improvement. One of the most interesting peculiarities of the model is that the global safety value is expressed through a fuzzy function. In fact, the main characteristics of the resulting function allow making a number of considerations on the actual performances of the building and obtaining a synthetic numeric index of the global safety level. The disaggregate values of the centres of gravity of the functions related to the workers' safety and health and hygiene safety ( 0.47 and 0.41 respectively) are also close to the average value.
The analysis of the data of each FA shows that processing and packaging FAs have values of the centres of gravity of HS fuzzy membership function significantly lower than the average value $(0.39$ and 0.33 respectively). In both cases, values are influenced by the high risk of pest contamination (Figure 5). Similarly, it is possible to highlight that, in the analysed case study, the Receiving area has a low value of OS (0.37) resulting from the high risk of slipping (Figure 5). These results show the need to perform corrective actions in the processing and packaging FAs in order to improve the hygienic conditions of these areas that are strategic to ensure the quality of products. At the same time, there is the need to better the OS in the receiving FA. To that purpose, pest intrusion barriers in the Processing and Packaging areas and slip resistance values in the Receiving area should be bettered.

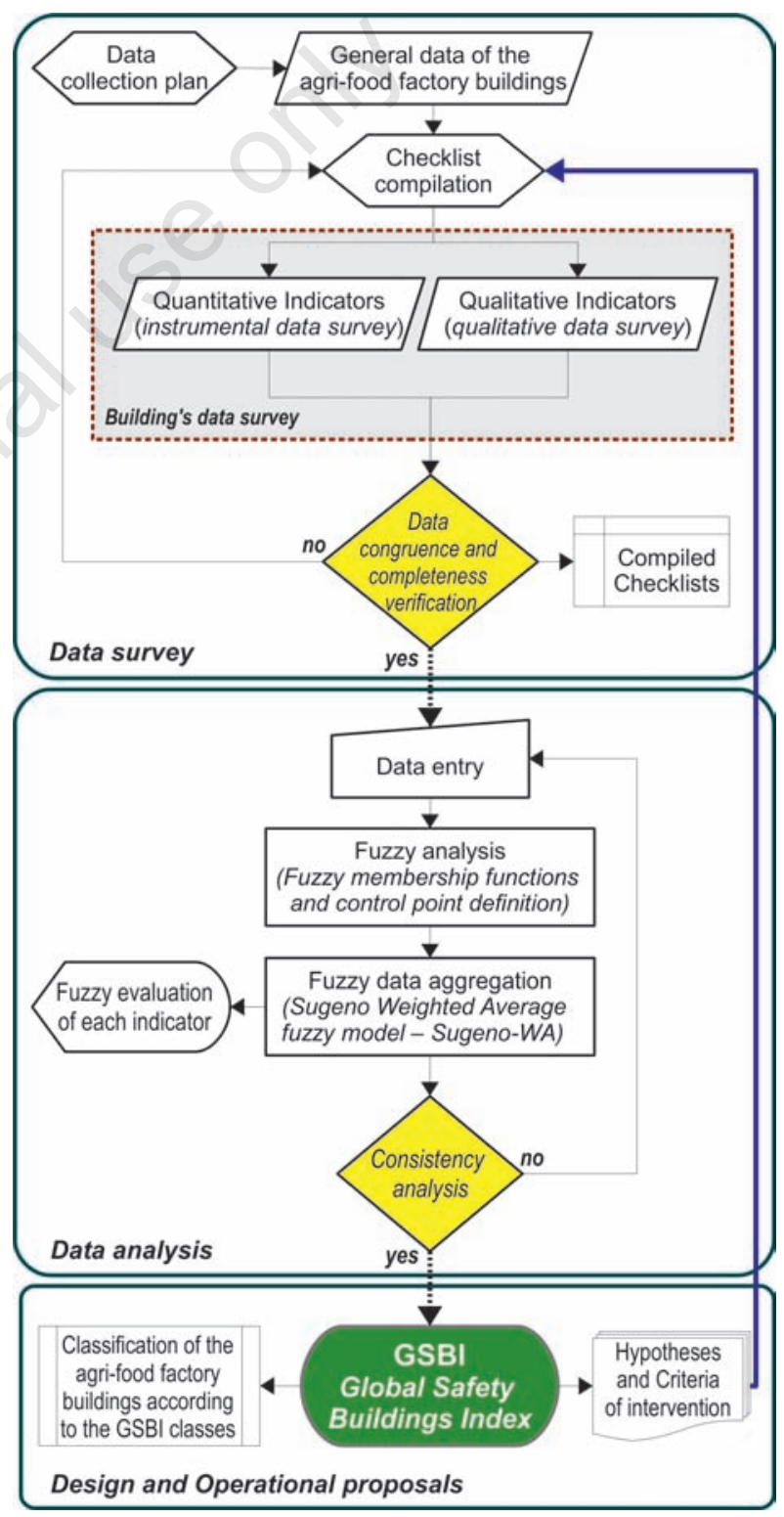

Figure 4. Flow-chart of the procedure implemented for the global safety buildings index assessment. 


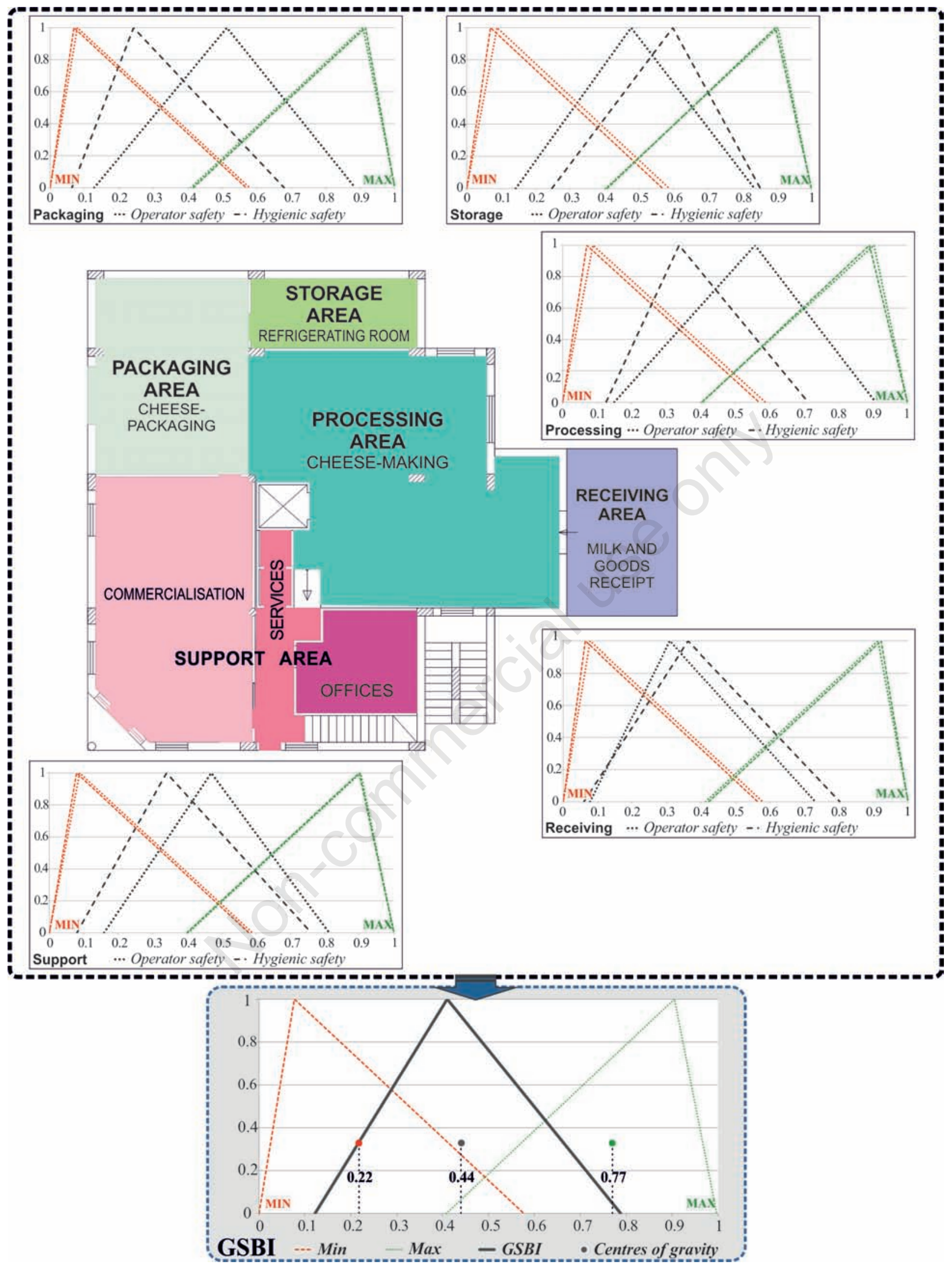

Figure 5. Lay-out of the surveyed dairy farm showing fuzzy membership functions of operator safety and hygienic safety for each functional area. The lower graph shows the fuzzy membership function and centre of gravity referring to the global safety building index (GSBI) value of the surveyed dairy farm. Min and Max are, respectively, minimum and maximum fuzzy membership functions set out in the model. 


\section{Conclusions}

Manufacturing facilities should ensure adequate performances in terms of health and hygiene standards and of workers' safety (Jacinto et al., 2009). These performances should be carefully taken into account during the building design process and regularly verified during its use. Hence, this paper proposes an assessment model that, based on an established study and on the application of a fuzzy logic procedure, allows assessing the global safety level of agri-food buildings by means of a GSBI. The model enables to obtain a synthetic and global value of the building performance for each of its FAs, in terms of food hygiene and workers' safety and welfare as well as to highlight possible weaknesses. A first implementation of the whole procedure to the manufacturing area of a dairy farm located in the plain of Gioia Tauro (Calabria, Italy) highlighted the appropriateness of the model and its ease of application. The developed procedure allowed organising and simplifying the measurements and surveys carried out inside the building, thus expediting the model application. The interpretation of the results from the model application was of the utmost importance. In fact, even though they were expressed through triangular fuzzy functions, their interpretation and comparison allowed getting a series of information on the possible weaknesses found in the building and considering improvements. The GSBI may be applied in either the design or the operational phase of a building in order to properly propose targeted building solutions ensuring a good level of hygienic safety and workers' safety. Finally, it is worth mentioning that the structure of the model allows necessary adjustments and improvements during all the phases of the process and it is so general that it may be applied to all types of agri-food production. Therefore, this study will be further developed to allow applying the model to other functional fields of the manufacturing facility and to various types of production. Future research will be focussed on the validation of such new applications and on specific sensitivity analyses of the indicators considered.

\section{References}

Abouelnaga A., Metwally A., Aly N., Naguib A., Nagy M., Agamy S. 2010. Assessment of nuclear energy sustainability index using fuzzy logic. Nuclear Engine. Desig. 240:2820-30.

Barreca F., Cardinali G., Di Fazio S. 2010. A model for the evaluation of building sustainability in agri-food industry. Sustainable Biosystems Through Engineering, 13-17 June 2010, XVII World Congr. Int. Commission of Agricultural and Biosystems Engineering, Québec City, Canada, pp 1-10.

Beriha G.S., Patnaik B., Mahapatra S., Padhee S. 2012. Assessment of safety performance in Indian industries using fuzzy approach. Expert Syst. Appl. 39:311-23.

Di Fazio S., Barreca F. 2009. Analisi prestazionale e sostenibilità edilizia nelle costruzioni rurali: aspetti metodologici e applicativi. Proc. IX Conv. Naz. AIIA, 12-16 September, Naples, Italy, pp 1-10.
Dioguardi L., Franzetti L. 2008. Influence of environmental conditions and building structure on food quality: A survey of hand-crafted dairies in Northern Italy. Food Control. 21:1187-93.

European Commission, 2007. Community strategy on health and safety at work (2007-2012). COM(2007) 62 final. Brussels. Available from: http://europa.eu/legislation_summaries/employment_and_social_ policy/health_hygiene_safety_at_work/110114_en.htm\#

Eurostat. 2010. Manufacture of food products statistics NACE Rev. 2. Available from: http://epp.eurostat.ec.europa.eu/statistics_ explained/index.php/ Manufacture_of_food_products_statistics_ NACE_Rev._2

Fabiano B., Currò F., Pastorino R. 2004. A study of the relationship between occupational injuries and firm size and type in the Italian industry. Safety Sci. 42:587-600.

Holeček P., Talašová J. 2010. FuzzME: a new software for multiple-criteria fuzzy evaluation. Acta Universitatis Matthiae Belii ser. Mathematics. 16:35-31.

Jacinto C., Canoa M., Guedes Soares C. 2009. Workplace and organisational factors in accident analysis within the Food Industry. Safety Sci. 47:626-35.

Joon-Hoa C., Vivianb L., Azizanb A. 2012. Post-occupancy evaluation of 20 office buildings as basis for future IEQ standards and guidelines. Energy Build. 46:167-75.

Lelieveld H.L.M., Mostert M.A., Holah J. 2005. Handbook of hygiene control in the food industry. ${ }^{\text {th }}$ rev. ed. Woodhead Publishing Limited, Cambridge, UK.

Leppälä J.M. 2012. Integrated production and safety risk management on. Proc. Int. Conf. Agricultural Engineering, July 8-12, Valencia, Spain, pp 1-6.

Malkin F., Harrison R. 1980. A small mobile apparatus for measuring the coefficient of friction of floors. J. Phys. D Appl. Phys. 13:77-9.

Mamdani E.H., Assilian S. 1975. An experiment in linguistic synthesis with a fuzzy logic controller. Int. J. Man-Machine Stud. 7:1-13.

Parejo-Moscoso J.M., Rubio-Romero J.C., Pérez-Canto S., SorianoSerrano M. 2013. Health and safety management in olive oil mills in Spain. Safety Sci. 51:101-8.

Pinto A., Ribeiro R., Nunes L. 2012. Fuzzy approach for reducing subjectivity in estimating occupational accident severity. Accident Anal. Prev. 45:281-90.

Porceddu P.R., Babucci V. 2007. Analysis of the main risk factors for workers' safety in some dairies. Riv. Ing. Agr. 38:9-15.

Seaman P. 2010. Food hygiene training: Introducing the food hygiene training model. Food Control. 21:381-7.

Sinisammal J., Belt P., Härkönen J., Möttönen M.,Väyrynen S. 2012. Managing well-being at work during 2010 - expert viewpoints. Open J. Safety Sci. Technol. 2:25-31.

Stave C., Törner M. 2007. Exploring the organisational preconditions for occupational accidents in food industry: a qualitative approach. Safety Sci. 45:355-71.

Takagi T., Sugeno M. 1985. Fuzzy identification of systems and its applications to modelling and control. IEEE Trans. Syst. Man Cybern. 15:116-32.

Zadeh L.A. 1965. Fuzzy sets. Inf. Control. 8:338-53. 